


\section{Why are health authorities concerned about home treatment of patients with sleep apnoea?}

\section{Educational aims}

1 To give an ovenview of the variability of home treatment for CPAP

1 To give insight into the reason for this variability

\section{Summary}

Although individual costs are low, the long-term treatment of patients with sleep apnoea has a large overall cost. In trying to assess the economic price of treatment of these patients, authorities need to consider many different aspects of the treatment, including the diagnosis, indications and patient compliance. However, this is complicated by the variability within these aspects. Although the number of patients has seen a steady increase, variability in diagnosis is dictated by efficient management of waiting lists. Variability of indications is more difficult to explain, although differences in diagnostic criteria and provision of service may have influence here. Finally, variability in compliance is a key aspect and must be considered during prescription of treatment.

Health authorities are interested in analysing the financing models for technologies applied to patients with chronic diseases because, although the unit costs are not very expensive, long-term use has a large economic impact [1]. Thus, the focus is on the overall cost (very high over time) and on the misuse of treatment (indication criteria and compliance). Moreover, since the number of patients is relatively constant over time (the number of new cases and treatment discontinuation are not very high), it is easier to monitor than in other treatments or care processes.

In the late 1980s, Catalan health authorities were interested in long-term home oxygen therapy (LTOT) from such a perspective. In this case, related to LTOT, the commissioner knew perfectly well:
- Indication criteria were based on objective data (two controlled trials published in 1980 and 1981) and everyone accepted that it was necessary to take an arterial blood gases sample, with the patient breathing room air, to decide oxygen prescription.

- The criteria for appropriate enforcement. It was difficult to assess but everybody agreed on the desirability of making LTOT $>15 \mathrm{~h} \cdot \mathrm{day}^{-1}$.

- The time perspective: LTOT improves survival of patients with chronic obstructive pulmonary disease (COPD) who have chronic hypoxaemia, but the improvement is not unlimited. This means that there is a balance between new cases and mortality, and the provision of care can take account of the following points:

\section{J. Escarrabill}

Master Plan for Respiratory Diseases -PDMAR- (Department of Health), Institut d'Estudis de la Salut, Barcelona, Spain

\section{Correspondence}

J. Escarrabill

Institut d'Estudis de la Salut Cl Roc Bornat, 81-95 1st floor 08005 Barcelona Spain

jescarrabill@gencat.cat 


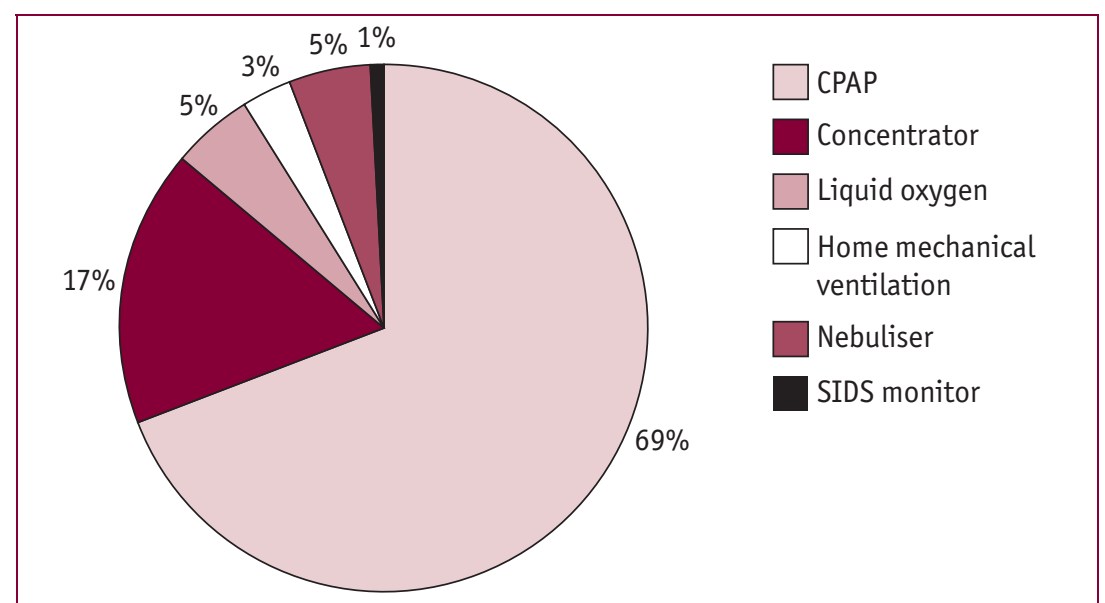

Figure 1

Patients on respiratory therapies at home in Catalonia (2009). $n=73,597$ patients. Data from the Catalan Health Institute (2010).

In a situation in which few patients receive treatment with LTOT, it is possible that, at any given time, there will be a sudden increase in cases (assuming a diagnosis improvement), but that the number gradually reach a plateau.

Growth over time is a vegetative growth after reaching the plateau.

In the case of LTOT, changes in the indication criteria are not foreseen in the immediate future, nor are there likely to be significant changes in technology (so it is very unlikely that there will be a sharp increase in the number of prescriptions).

The proposed financing system included the definition of the indication criteria, the identifica-

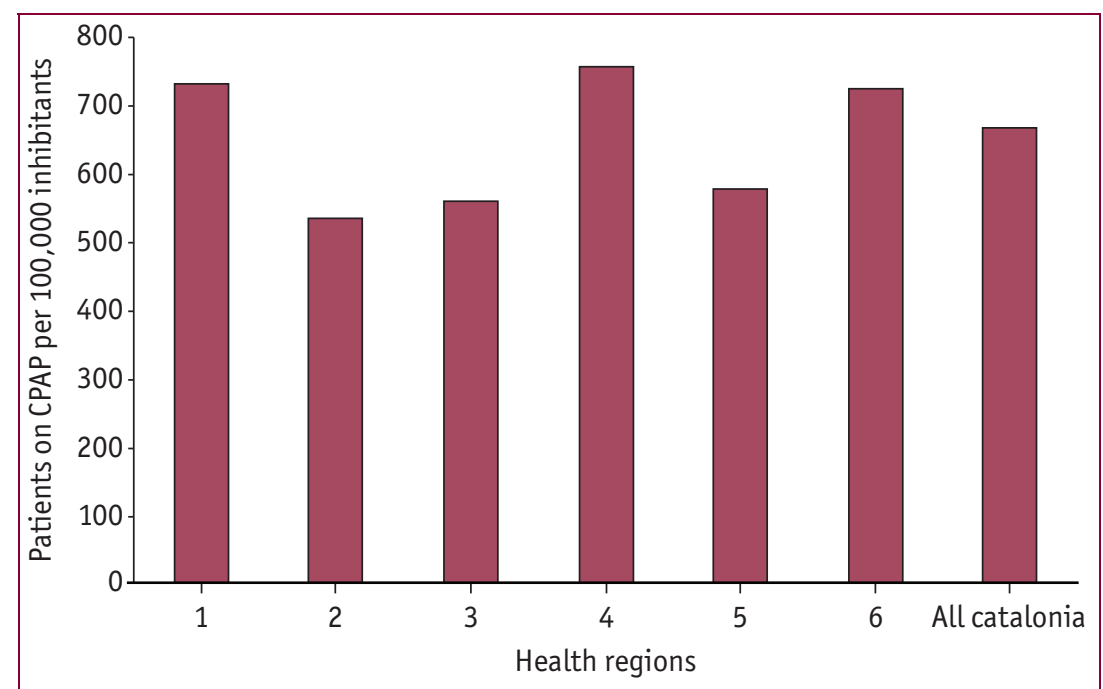

Figure 2

Variability across health regions in Catalonia (2009). $n=50,835$. Data from the Catalan Health Institute (2010). tion of prescribers, a portfolio of specific services and regular monitoring mechanisms. In addition, a technical expert working group should respond to the problems that could arise. The aim was to achieve a balance between accessibility to all sources of oxygen supply, the appropriate use of treatment [2] and the efficient use of resources allocated to this treatment.

The financing policies for service provision addressed three issues:

- Degree of coverage of health provision.

- Well-defined clinical indications.

- Budget available and prioritisation of the use of scarce resources:

- Position with regard to improper use.

- Criteria regarding the introduction of new techniques.

\section{Early use of CPAP}

The relationship between obesity and hypersomnolence has been known since ancient times [3]. But in 1981, Sullivan described the benefits of applying continuous positive airway pressure (CPAP)(through the nose) to avoid the collapse of the upper airway and to improve the symptoms of obstructive sleep apnoea [4].

In the first years of treatment with CPAP, the indication and home treatment were assimilated into the LTOT for several reasons:

- Pulmonologists (some of whom regularly prescribed LTOT) were quickly interested by the problem of sleep disorders.

- Sleep disorder therapy required devices including consumables (masks) and followup for repair or quality control material. This situation is equivalent to the service of LTOT.

- In many countries, companies supplying LTOT took charge of supply and technical control of CPAP devices.

In the early years, clinical uncertainties worried health authorities:

- There was no consensus on diagnostic criteria:

- In many cases, the diagnosis was made without full polysomnography (or respiratory polygraphy) and most prescriptions were based on pulse oximetry graphics drawn with a very crude quantification.

Experience with full polysomnography was very limited and researchers were trying to validate new diagnostic tools.

- The time horizon was determined by the types of patients: 
- Much younger than the population with LTOT.

- Much longer than expected survival.

- Early epidemiological studies suggested the need for CPAP to a very high percentage of the population.

- Progressive emergence of new potential beneficiaries (patients with stroke, heart disease, hypertension, etc.).

- Uncertainties in compliance.

Probably the most disconcerting factor for health authorities was the lack of consensus among professionals regarding diagnostic criteria. MCNicholas [5] recognised in 1996 that there was no consensus on the number of apnoeas/hypopnoeas that have clinical significance in obstructive sleep apnoea syndrome [6]. In 1997, experts were still discussing the CPAP treatment time necessary to obtain clinical benefits. HeRs et al. [7] suggested that the use of CPAP for $\geqslant 4 \mathrm{~h} \cdot$ night $^{-1}$ could provide clinical benefits.

Faced with clinical uncertainties (real or perceived), the health administration took a precautionary approach: limiting the number of prescribers and putting in place an upper financial limit, the benefit of which was very small for the suppliers. This attitude can be helpful in containing costs, but it does not guarantee that the sickest patients are the first receiving treatment.

Now there are accepted criteria to deal with sleep disorders $[8,9]$.

In Catalonia (7.3 million inhabitants), $>60,000$ patients receive home therapy with CPAP. The number of patients treated at home for sleep apnoea represents more than two-thirds of the entire number of patients on respiratory treatments at home (fig. 1).

\section{Some questions raised by the commissioner}

The commissioner may raise various issues around the care of patients with sleep disorders.

\section{Diagnosis}

The diagnosis of sleep disorders poses several problems from the standpoint of the commissioner. Although it may seem paradoxical, the main problem is not the number of patients (despite the steady increase seen in recent years). The funding problem is to make sure that the most efficient diagnostic method is used and that the most severely ill patients are the first served.

The efficient use of diagnostic methods is related to waiting lists. Three years ago, the waiting time for the first visit in Spain was 2 months and the waiting time for a full polysomnography was $>5$ months [10]. These waiting times are not very different from those reported by Flemons et al. [11] in Canada, Australia, the UK, or Belgium. In some cases, there is a third waiting time: from the time of diagnosis to initiation of treatment, which includes the visit and procedure for certification of the level of CPAP. Thus, from the time the patient is referred to a specialised centre until the start of treatment, it could take $>7-8$ months. The commissioner has to cope with this discrepancy between supply and demand.

Health authorities have sought alternatives in order to solve these problems. Screening studies at home may reduce the need for complex studies. Strengthening the role of nurses to treat less severe cases can reduce waiting times for severe patients [12] Improving the level of CPAP titration also improves time management [13].

In a context where there is a chronic resource limitation, the prioritisation of healthcare is essential. The commissioner has an interest in treating the sickest patients. In the case of sleep disorders, that interest is due to the efficient use of resources but also to the medicallegal aspects related to the social impact of undertreatment [14].

\section{Variability of indications}

As in most clinical practice, a large variability in the indication of CPAP is found. The extraordinary variability noted in the indications of CPAP may be related to several factors. At the beginning, the lack of consensus in diagnostic criteria was a crucial factor; however, in some areas the introduction of high-level diagnostic technology was made in relation to the positive interest of physicians in the field or designers of equipment and devices, rather than in relation to systematic planning.

It is not easy to explain that the number of sleep studies per 100,000 population is so different between and within countries. In the UK, there are 42.5 sleep studies per 100,000 inhabitants and, in the USA, there are 427 sleep studies per 100,000 inhabitants [15].

In Catalonia (population 7.3 million), the number of patients with CPAP is 0.7 per 100 
inhabitants. Figure 2 shows the variability between health regions in regard to the number of patients using CPAP. In this case, the variability cannot be explained by problems of access (most of the population live $<30 \mathrm{~km}$ from a hospital) or by funding problems (the public system is responsible for all cost of diagnosis and treatment for all the population).

The variability in access to senvices (when there is no physical or financial limitations), from the payer perspective, also raises questions of equity concerning the distribution of resources.

\section{Compliance}

Compliance is a key element to ensure the efficient use of scarce resources. For years, physicians have known that patients make a partial use of the CPAP and many studies have found that most patients use the device for 3-6 h. night ${ }^{-1}$ [16]. In patients who are undergoing treatment properly, it appears that time with CPAP increases year after year from the second year of treatment. This could be a kind of the so called "Matthew effect" [17] applied to CPAP: those who perform well the treatment will do better still [18].

To improve compliance, direct support seems more useful than the use of devices that adjust automatically [19].

Educational, behavioural and supportive interventions can improve usage of CPAP devices for obstructive sleep apnoea with adults [20]. In any case, the prescription of CPAP to treat sleep apnoea must include plans to improve compliance and plans to identify patients who do not use it systematically, in order to achieve proper compliance or otherwise decide to stop the funding of treatment.

\section{Monitoring of patients}

Several studies indicate that there is a variable percentage of patients who drop out or fail to start treatment [21]. CPAP patients requiring follow-up may prevent dropouts and promote systematic use of treatment.

Monitoring and following up the treatment of sleep disorders involves many health professionals and technicians. A specialised team, community health resources and suppliers of the devices have a role in the screening, diagnosis, monitoring and follow-up of patients. However, a wide range of professionals may also have their role; nutritionists, ear, nose and throat specialists, neurologists or psychiatrists, and others may participate in the diagnosis or part of treatment.
From a general point of view, it does not make sense to control a disease as prevalent as sleep disorders exclusively at the hospital. The role of specialised team is clear in the diagnosis and in the titration. However, in practice, it is necessary to design the most appropriate caregiving network in each country. To care on distributed networks is the most reasonable theoretical proposal.

It is estimated that $23-32 \%$ of patients seen in general practice consultation may have some risk factor associated with sleep disorders [22]. Therefore, in this distributed network of health facilities, primary care plays an important role. The dilemma arises in the definition of a care model. Some professional sectors think that patients who use CPAP must be cared for by the general practioner (as any patient with a chronic illness), but others believe that it is necessary to create a specific team parallel to primary care (performed mainly by nurses) to do the monitoring. In some countries, it is questionable whether the supplier of the product may play a role in monitoring or not.

\section{Sleep apnoea in children}

Attention to diagnosis and treatment of sleep problems in children has not received the same interest as in adults $[23,24]$. It is possible that firstline paediatricians do not provide the same attention to sleep problems that they do to feeding problems or growth. Therefore, referrals to specialised centres are lower.

$0.7-1.8 \%$ of children may have problems related to obstructive sleep apnoea which, although moderate, may have a significant neuropsychological impact [25].

Tonsillectomy solves the problem in many cases and, unlike in the adult, CPAP is a secondline treatment in cases for which surgery is not indicated.

For these reasons, in paediatrics, suspicion and diagnosis have a much more crucial role that the long-term follow-up, compared with the adult in which both components are very important.

\section{Form of financing}

The delivery of senvice is also very diverse: organised from within the hospital, through nonprofit organisations or through private companies, with varying degree of participation in the monitoring of the patient (in some cases, the private company provides only the material or, in others, they also perform the regular monitoring 
of the patient). Nowadays, in most European countries, the form of funding is based on the payment for the senvice, regardless of the result obtained, directly or indirectly assumed by the public health system (either through a national health service or insurers in the social security model).

In this type of service, it is not easy to define objectively the acceptable results of treatment. The level of compliance alone does not necessarily correlate with symptom improvement. Survival is the best result to value, but it is not practical from the point of view of funding. However, it is desirable to design a payment method that would create incentives both good indication of the effective use of treatment. This funding model should involve both clinical (prescribers) and home-senvice providers. Payment by result will improve compliance and will avoid paying for patients who do not use the equipment.

\section{Legal implications}

Health authorities are also pending of legal issues related to the diagnosis and prescription (or infra-prescription) for the treatment of sleep disorders. Sleepiness is associated with an increased risk of traffic accidents. The legislation is variable with respect to driving but in any case, the responsible for advising the patient should be the physician [26]. The adequate attitude towards patients with sleep disorders who refuse treatment and continue driving vehicles is not clear. Perhaps the only choice would be to promote a European Directive on sleep disorders and driving [27].
In addition to traffic accidents, sleepiness is also associated with more accidents at home or in the workplace [28].

In this context, waiting lists for both the diagnosis and initiation of treatment or monitoring are a problem for the commissioner and clinicians. First, it is necessary to provide resources to respond to the needs (the commissioner) and secondly it is mandatory to try to ensure the efficient use of resources with a proper selection of patients according to severity and needs (the clinician).

\section{Conclusions}

Most European health systems are based on a significant weight of public provision of health services, either through the national health system or through the social security system. In any case, the solutions suggested by context of liberal provision of health services, as in the case of the USA, cannot be extrapolated automatically.

EPSTEIN and VAlENTINE [29] proposed the establishment of "sleep centers" to be adapted to market needs. It may be questioned the promotion of centres for the diagnosis and treatment of sleep disorders that are not integrated into the entire health system. However, it is interesting in any context to identify the performance parameters that define the efficient practice: demographics, satisfaction, resolution capabilities, cost and quality, among others.

There are two crucial aspects to be addressed in the following two articles in this issue of Breathe: the role of primary care in the screening and follow-up of patients with sleep disorders and the simplified diagnostic methods.

\section{References}

1. Borras JM, Granados A, Escarrabill J, et al. Complex decisions about an uncomplicated therapy: reimbursement for long-term oxygen therapy in Catalonia (Spain). Health Policy 1996; 35: 53-59.

2. Granados A, Escarrabill J, Borrás JM, et al. The importance of process variables analysis in the assessment of longterm oxygen therapy by concentrator. Respir Med 1997; 91: 89-93.

3. Guilleminault C, Eldridge FL, Tilkian A, et al. Sleep apnea syndrome due to upper airway obstruction: a review of 25 cases. Arch Intern Med. 1977; 137: 296-300.

4. Sullivan CE, Issa FG, Berthon-Jones M, et al. Reversal of obstructive sleep apnoea by continuous positive airway pressure applied through the nares. Lancet. 1981; 1: 862-865.

5. McNicholas WT. Diagnostic criteria for the sleep apnoea syndrome: time for consensus. Eur Respir J. 1996; 9: 634635.

6. Wright J, Johns R, Watt I, et al. Health effects of obstructive sleep apnoea and the effectiveness of continuous positive airways pressure: a systematic review of the research evidence. BMJ. $1997 ; 314: 851-860$.

7. Hers V, Liistro G, Dury M, et al. Residual effect of nCPAP applied for part of the night in patients with obstructive sleep apnoea. Eur Respir J. 1997; 10: 973-976.

8. Epstein LJ, Kristo D, Strollo PJ, et al. Clinical guideline for the evaluation, management and long-term care of obstructive sleep apnea in adults. J Clin Sleep Med 2009; 5(3): 263-276.

9. Fleetham J, Ayas N, Bradley D, et al. Canadian Thoracic Society guidelines: diagnosis and treatment of sleep disordered breathing in adults. Can Respir J. 2006; 13: 387-392. 
10. Masa Jiménez JF, Barbé Illa F, Capote Gil F, et al. Recursos y demoras en el diagnóstico del síndrome de apneashipopneas durante el sueño (SAHS). Arch Bronconeumol. 2007; 43: 188-198.

11. Flemons WW, Douglas NJ, Kuna ST, et al. Access to diagnosis and treatment of patients with suspected sleep apnea. Am J Respir Crit Care Med. 2004; 169: 668-672.

12. Antic NA, Buchan C, Esterman A, et al. A randomized controlled trial of nurse-led care for symptomatic moderatesevere obstructive sleep apnea. Am J Respir Crit Care Med. 2009; 179: 501-508.

13. Masa JF, Jiménez A, Durán J, et al. Alternative methods of titrating continuous positive airway pressure: a large multicenter study. Am J Respir Crit Care Med. 2004; 170: 1218-1224.

14. Pack AI. Sleep-disordered breathing: access is the issue. Am J Respir Crit Care Med. 2004; 169: 666-667.

15. Marshall NS, Wilsmore BR, McEvoy RD, et al. Polysomnography in Australia--trends in provision. J Clin Sleep Med. 2007; 3: 281-284.

16. McNicholas WT. Compliance with nasal CPAP therapy for obstructive sleep apnoea: how much is enough? Eur Respir J. 1997; 10: 969-970.

17. Merton, Robert K. The Matthew Effect in Science. The reward and communication systems of science are considered. Science 1968; 159: 56-63.

18. Sucena M, Liistro G, Aubert G, et al. Continuous positive airway pressure treatment for sleep apnoea: compliance increases with time in continuing users. Eur Respir J. 2006; 27: 761-766.

19. Damjanovic D, Fluck A, Bremer $H$, et al. Compliance in sleep apnoea therapy: influence of home care support and pressure mode. Eur Respir J. 2009; 33: 804-811.

20. Smith I, Nadig V, Lasserson TJ. Educational, supportive and behavioural interventions to improve usage of continuous positive airway pressure machines for adults with obstructive sleep apnoea. Cochrane Database Syst Rev. 2009; 2: CD007736.

21. Wolkove N, Baltzan M, Kamel $\mathrm{H}$, et al. Long-term compliance with continuous positive airway pressure in patients with obstructive sleep apnea. Can Respir J. 2008; 15: 365-369.

22. Skjodt NM. Approach to outpatient management of adult sleep apnea. Can Fam Physician 2008; 54: 1408-1412.

23. Section on Pediatric Pulmonology, Subcommittee on Obstructive Sleep Apnea Syndrome. American Academy of Pediatrics Clinical practice guideline: diagnosis and management of childhood obstructive sleep apnea syndrome. Pediatrics. 2002; 109: 704-712.

24. Muzumdar H, Arens R. Diagnostic Issues in Pediatric Obstructive Sleep Apnea. Proceedings of the ATS 2008; 5 : 263-273.

25. Powell S, Kubba H, O'Brien C, et al. Paediatric obstructive sleep apnoea. BMJ 2010; 340: c1918.

26. Krieger J. Sleep apnoea and driving: how can this be dealt with? Eur Respir Rev 2007; 16: 189-195.

27. Alonderis A, Barbé F, Bonsignore M, et al. COST Action B-26. Medico-legal implications of sleep apnoea syndrome: driving license regulations in Europe. Sleep Med. 2008; 9: 362-375.

28. Krieger J, McNicholas WT, Levy P, et al. Public health and medicolegal implications of sleep apnoea. Eur Respir J. 2002; 20: 1594-1609.

29. Epstein LJ, Valentine PS. Starting a sleep center. Chest. 2010; 137: 1217-1224. 